\title{
ESTUDO DA QUALIDADE DA ÁGUA SUBTERRÂNEA NA ÁREA DE INFLUÊNCIA DO ATERRO SANITÁRIO METROPOLITANO OESTE DE CAUCAIA, ESTADO DO CEARÁ
}

Edilson Holanda Costa Filho ${ }^{1}$; Marilângela da Silva Sobrinho' ${ }^{1}$ Denise Maria Rodrigues Guilherme ${ }^{1}$; Magda Maria Marinho ${ }^{1}$

Resumo - O objetivo desse trabalho foi verificar a influência na qualidade da água subterrânea pela disposição de resíduos sólidos em um aterro sanitário da cidade de Caucaia, estado do Ceará. O aterro possui 06 poços de monitoramento da água subterrânea, cujos resultados das análises são enviados periodicamente ao órgão governamental responsável pelo licenciamento ambiental no Ceará (SEMACE). Para comparar com os resultados enviados pelo aterro, a SEMACE analisou a água de 08 poços localizados fora do perímetro interno do empreendimento. Os resultados mostraram indícios do comprometimento da qualidade da água dos poços monitorados na área interna do aterro, principalmente em relação à concentração de Cloretos, Sólidos Totais Dissolvidos, Compostos Nitrogenados e Demanda Bioquímica de Oxigênio. Dentre os metais analisados, ferro e manganês apresentaram-se acima do limite máximo permitido em alguns momentos nos poços internos. Também foi analisado o efluente do sistema de tratamento de chorume cujos resultados também apresentaram parâmetros fora do padrão estabelecido na legislação vigente.

Abstract - The aim of this study was to verify the influence in the ground water quality by solid waste disposal in a landfill, located in Caucaia city, state of Ceará. The landfill has 06 monitoring wells and the results are frequently sent to the government bureau responsible for the environmental licensing in the state of Ceará (SEMACE). To compare the results sent by landfill, the SEMACE analyzed the ground water from 08 wells located outside the landfill. The results showed that the ground water inside the landfill probably had been damaged by the solid waste disposal, especially regarding to Chloride, Total Dissolved Solid, Nitrogenous Compounds and Biochemical Oxygen Demand. Among the metals analyzed, $\mathrm{Fe}$ and $\mathrm{Mn}$, in some moments, showed results above of the standard established in legislation. The effluent from the leachate system treatment was also analyzed and the results showed some parameters with concentrations above the standard established in legislation.

Palavras-Chave - Aterro sanitário, água subterrânea, contaminação.

${ }^{1}$ Superintendência Estadual do Meio Ambiente, Rua Jaime Benévolo 1400, Fátima, Fortaleza, Ceará, 85-3101-5514, edilson.holanda@ semace.ce.gov.br 


\section{1 - INTRODUÇÃO}

No Brasil, a água subterrânea é intensamente explorada, onde 15,6\% dos domicílios utilizam exclusivamente água subterrânea, 77,8\% usam rede de abastecimento e 6,6\% usam outras formas. Destaca-se que, entre os domicílios que possuem rede de abastecimento de água, uma parte significativa também usa água subterrânea. Embora o uso do manancial subterrâneo seja complementar ao superficial em muitas regiões, em outras áreas do país, a água subterrânea representa o principal manancial hídrico e desempenha importante papel no desenvolvimento socioeconômico do país (Biguelini e Gumy, 2012).

Diante da importância do manancial subterrâneo, não é difícil concluir que também é necessário a sua proteção. Apesar de menos suscetível a degradação do que os mananciais superficiais, as águas subterrâneas não estão totalmente imunes à ação depredatória do homem. Diversas são as fontes possíveis de contaminar um lençol freático de uma região, e entre elas destaca-se a disposição de resíduos sólidos no solo.

Segundo Santos et al. (2004), a disposição final inadequada de resíduos sólidos, causa, dentre outros problemas, a contaminação do solo, dos recursos hídricos superficiais e subterrâneos, além da degradação de ecossistemas aquáticos e terrestres, com consequente redução da qualidade de vida dos aglomerados urbanos. A contaminação dos recursos hídricos superficiais e subterrâneos em áreas de disposição de resíduos sólidos urbanos é causada principalmente pelo líquido percolado dos aterros (chorume), que é uma mistura de compostos orgânicos e inorgânicos, nas suas formas dissolvidas e coloidais, formado pela decomposição anaeróbia da matéria orgânica e por elementos presentes nos resíduos.

Mor et al. (2006) relata que as áreas próximas aos aterros sanitários têm maior possibilidade de contaminação da água subterrânea, o que implica em risco substancial aos usuários locais deste recurso e ao ambiente natural. A qualidade da água subterrânea na área de influência dos aterros sanitários deve atender aos padrões de potabilidade estabelecidos pela legislação vigente, conforme recomendações da norma NBR 13896:1997 da Associação Brasileira de Normas Técnicas (ABNT, 1997). Atualmente está em vigor a Resolução do Conselho Nacional do Meio Ambiente No 396, de 03 de abril de 2008, que dispõe sobre a classificação e diretrizes ambientais para o enquadramento das águas subterrâneas e dá outras providências.

A Superintendência Estadual do Meio Ambiente (SEMACE) é o órgão responsável pelo licenciamento de aterros sanitários no estado do Ceará, quando os resíduos depositados são provenientes de mais de um município, caso do aterro Sanitário Metropolitano Oeste de Caucaia (ASMOC), ou quando o município não possui órgão ambiental.

Segundo o Relatório de Impacto Ambiental (RIMA) do ASMOC, apresentado em 1989 à SEMACE, a formação geológica da área estudada é constituída basicamente por rochas cristalinas que 
podem ser divididas em duas séries: a mais atingida é formada por migmático com penetração de granito e outra, mais recente, formada por gnaisse e micaxisto. Nessa área ocorre predominância absoluta de gnaisses e de migmatitos sobre as demais rochas encontradas em virtude de pertencerem ao período Pré-Cambriano Indiviso (Aquino, 1989).

Conforme Aquino (1989), a área é composta pela formação “Grupo Barreiras”, que se apresenta em forma de Tabuleiros morfologicamente uniformes, porém com grande variação no tocante à granulometria dos sedimentos. Caracteriza-se por depósitos de granulometria variada e composição mais freqüente de argila, areias e até conglomerados, em proporções variáveis, de consolidação fraca e cores predominantemente avermelhadas ou amareladas. O aqüífero da área em estudo é do grupo Barreiras e ocupa uma área de $817 \mathrm{~km}^{2}$ repousando diretamente sobre os xistos e gnaisses do embasamento cristalino.

Ainda de acordo com Aquino (1989), nos terrenos cristalinos a presença de água subterrânea está diretamente ligada aos fendilhamentos, mantas de intemperismo e "pedimentos detríticos".

Este trabalho, portanto, teve por objetivo verificar se a disposição de resíduos sólidos urbanos no ASMOC está causando impacto ambiental na qualidade das águas subterrâneas de sua área de influência. Os dados foram obtidos a partir dos relatórios de monitoramento da qualidade da água subterrânea na área interna do aterro, os quais são enviados, periodicamente, à SEMACE pela empresa responsável pela operação do equipamento, em cumprimento as condicionantes das licenças ambientais emitidas. A água dos poços localizados fora do perímetro interno do aterro foram coletadas e analisadas pela SEMACE.

\section{2 - OBJETIVOS}

Este trabalho teve por objetivo verificar se há impacto ambiental na qualidade das águas subterrâneas pela disposição de resíduos sólidos urbanos no aterro sanitário metropolitano oeste de Caucaia, na região metropolitana de Fortaleza, o qual recebe os resíduos oriundos desses dois municípios.

\section{3 - METODOLOGIA}

O aterro sanitário metropolitano oeste de Caucaia possui 06 poços de monitoramento da água subterrânea dentro da área de operação, de acordo com a Tabela 01, a seguir: 
Tabela 01: Nomenclatura e localização dos poços de monitoramento na área interna do aterro, sendo $\mathrm{AM}$ os poços a montante e $\mathrm{AJ}$ os poços a jusante

\begin{tabular}{cccc}
\hline POÇO & PROFUNDIDADE & Nível d'água & $\begin{array}{c}\text { GEORREFERENCIAMENTO } \\
\text { DATUM SAD 69 }\end{array}$ \\
\hline $01 \mathrm{AM}$ & $16,00 \mathrm{~m}$ & - & $536411 \mathrm{E} / 9580034 \mathrm{~N}$ \\
$02 \mathrm{AM}$ & $20,00 \mathrm{~m}$ & $5,00 \mathrm{~m}$ & $536822 \mathrm{E} / 9579831 \mathrm{~N}$ \\
$03 \mathrm{AM}$ & $20,00 \mathrm{~m}$ & $3,30 \mathrm{~m}$ & $537156 \mathrm{E} / 9580514 \mathrm{~N}$ \\
$01 \mathrm{AJ}$ & $8,00 \mathrm{~m}$ & $4,35 \mathrm{~m}$ & $536184 \mathrm{E} / 9581147 \mathrm{~N}$ \\
$02 \mathrm{AJ}$ & $4,85 \mathrm{~m}$ & $3,85 \mathrm{~m}$ & $535804 \mathrm{E} / 9580991 \mathrm{~N}$ \\
$03 \mathrm{AJ}$ & $38,00 \mathrm{~m}$ & $2,70 \mathrm{~m}$ & $536025 \mathrm{E} / 9581251 \mathrm{~N}$ \\
\hline
\end{tabular}

Em consequência do licenciamento ambiental desse aterro, a empresa responsável pela sua operação é obrigada a monitorar, bimestralmente, a qualidade da água desses seis poços e apresentar à SEMACE os laudos de análises. O presente artigo estudou os resultados apresentados entre os meses de agosto de 2014 e setembro de 2015.

Para verificar a influência da operação do aterro além dos limites do seu perímetro, em janeiro de 2016 a SEMACE coletou amostras de água de 08 poços externos a área do aterro, de acordo com a Tabela 02, a seguir.

Tabela 02: Nomenclatura e localização dos poços de monitoramento na área externa do aterro

\begin{tabular}{cc}
\hline POÇO & $\begin{array}{c}\text { GEORREFERENCIAMENTO } \\
\text { DATUM SAD 69 }\end{array}$ \\
\hline 01 & $535055 \mathrm{E} / 9582038 \mathrm{~N}$ \\
02 & $535108 \mathrm{E} / 9581932 \mathrm{~N}$ \\
03 & $535111 \mathrm{E} / 9581865 \mathrm{~N}$ \\
04 & $535693 \mathrm{E} / 9581789 \mathrm{~N}$ \\
05 & $535678 \mathrm{E} / 9581686 \mathrm{~N}$ \\
06 & $536630 \mathrm{E} / 9581612 \mathrm{~N}$ \\
07 & $537861 \mathrm{E} / 9580669 \mathrm{~N}$ \\
08 & $537854 \mathrm{E} / 9580596 \mathrm{~N}$ \\
\hline
\end{tabular}

Esses poços externos não foram construídos com a finalidade de monitoramento ambiental, conforme recomenda a norma NBR 15495, partes 1 e 2, da Associação Brasileira de Normas Técnicas. São poços artesianos, existentes em domicílios localizados nos arredores do aterro. Por isso não se sabe a profundidade dos mesmos. 
A Figura 01, a seguir, mostra a imagem obtida a partir do software Google Earth, de 31 de julho de 2015, onde observa-se o aterro sanitário e os poços de monitoramento internos e externos.

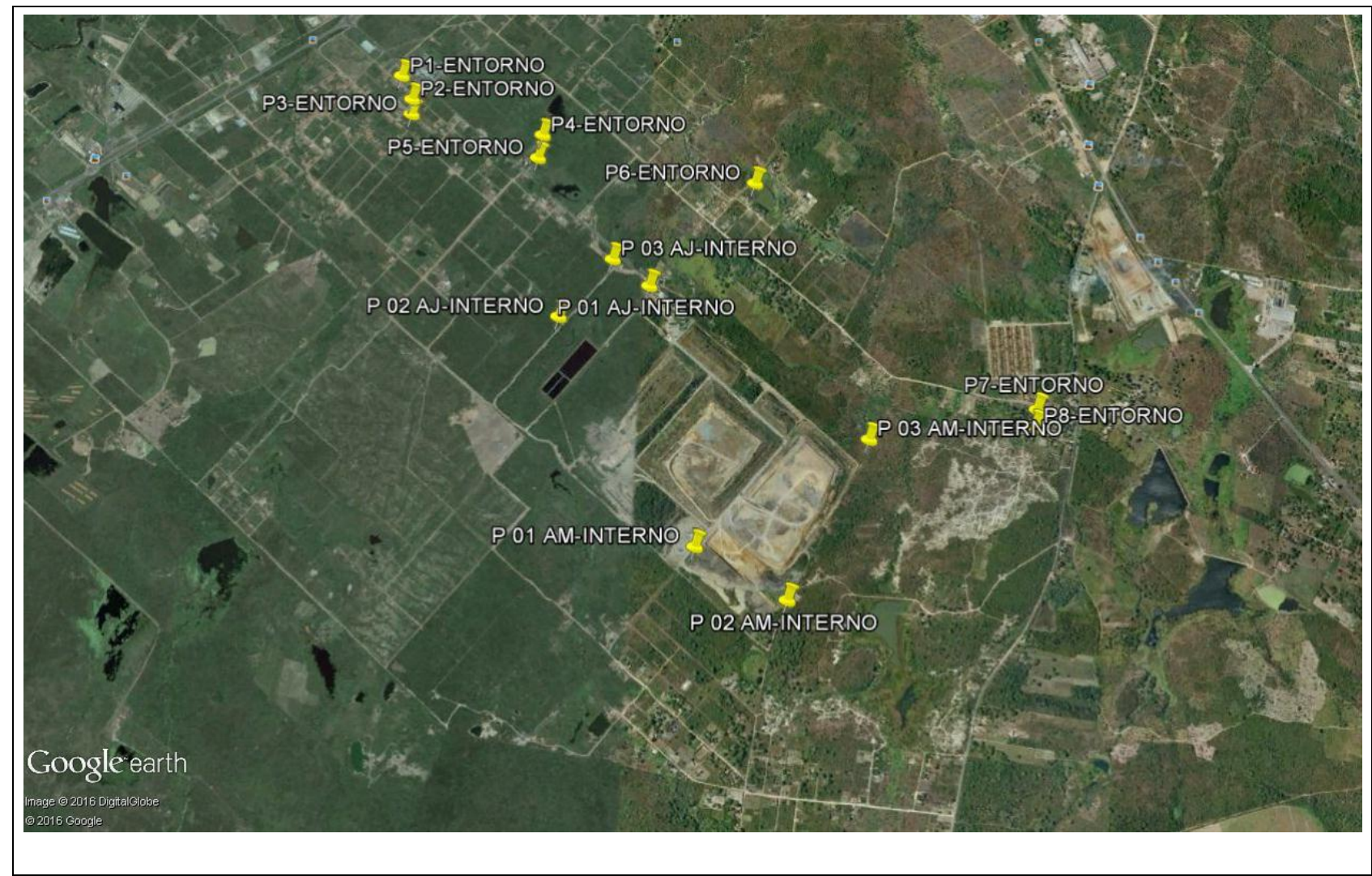

Figura 01: Imagem do ASMOC com os poços de monitoramento internos e externos (Fonte Google Erath, 2015)

Após a obtenção dos resultados, analisou-se o comportamento dos parâmetros que, em algum momento, apresentaram-se em desacordo com a legislação ambiental vigente, quais sejam: cloretos, compostos nitrogenados (amônia, nitrito e nitrato), sólidos totais dissolvidos, Demanda Bioquímica de Oxigênio (DBO), Demanda Química de Oxigênio, Ferro e Manganês.

Esse aterro também possui um sistema de tratamento de chorume constituído de 3 lagoas de estabilização, sendo duas anaeróbias e uma facultativa. A lagoa facultativa é a última do sistema de tratamento, a partir da qual o efluente seria lançado tratado no recurso hídrico. Entretanto, segundo informações do operador do aterro, não há mais lançamento em recurso hídrico e sim uma recirculação para o topo das trincheiras a partir da primeira lagoa anaeróbia. De qualquer forma, também analisouse a concentração dos parâmetros acima mencionados no efluente contido na lagoa facultativa, a partir dos dados apresentados pelo operador do aterro entre os meses de agosto de 2014 e setembro de 2015.

Assim, descreve-se a seguir os procedimentos analíticos utilizados na obtenção dos resultados desses parâmetros. 


\section{1 - Cloretos}

O procedimento de análise de Cloretos seguiu o descrito por Pohling, Ferreira e Farias (2005). Transferiu-se $50 \mathrm{~mL}$ da amostra para um erlenmeyer de $250 \mathrm{~mL}$. Adicionou-se $1 \mathrm{~mL}$ da solução de $\mathrm{K}_{2} \mathrm{CrO}_{4}$ e titulou-se com solução padrão de $\mathrm{AgNO}_{3} \quad 0,0141 \mathrm{~N}$ até o ponto final de cor marromvermelha. Titulou-se também um branco composto de $50 \mathrm{~mL}$ de água pura e $1 \mathrm{~mL}$ de indicador fenolftaleína.

Padronizou-se a solução de $\mathrm{AgNO}_{3}$ 0,0141N transferindo $20 \mathrm{~mL}$ da solução padrão de $\mathrm{NaCl}$ $0,0141 \mathrm{~N}$ para um erlenmeyer de $250 \mathrm{~mL}$ e diluiu-se com $100 \mathrm{~mL}$ de água pura. Acrescentou-se $1 \mathrm{~mL}$ de fenolftaleína e titulou-se com solução de $\mathrm{AgNO}_{3}$ 0,0141N. Dessa forma calculou-se o fator (normalidade) da solução $\mathrm{AgNO}_{3}$ através da fórmula $\mathrm{F}=\mathrm{A} /(\mathrm{C} \mathrm{x} \mathrm{B})$, em que A é o volume de $20 \mathrm{~mL}$ da solução de $\mathrm{NaCl}, \mathrm{B}$ é o volume gasto da solução de $\mathrm{AgNO}_{3}$ com o branco e $\mathrm{C}$ é o volume gasto de $\mathrm{AgNO}_{3}$ com a titulação.

O padrão de $\mathrm{NaCl} 0,0141 \mathrm{~N}$ foi feito dissolvendo $0,8240 \mathrm{~g}$ de $\mathrm{NaCl}$ (seco em $140{ }^{\circ} \mathrm{C}$ e 2 horas) em água pura no balão volumétrico, completando até a marca de aferição.

Feito isso, calculou-se a concentração de cloretos, em $\mathrm{mg} / \mathrm{L}$, através da fórmula $\mathrm{mgCl}^{-} / \mathrm{L}=[(\mathrm{C}-$ B) $x$ 0,5 x F 1000$] / \mathrm{mL}$ da amostra.

\section{2 - Sólidos Totais Dissolvidos}

Os Sólidos Totais Dissolvidos foram medidos utilizando-se uma sonda multi-parâmetro HQ 40d da marca HATCH, pelo método eletrométrico. A amostra de água é transferida para um béquer de 50 $\mathrm{mL}$ e na sequência mergulha-se a sonda na água, fazendo-se a leitura no visor do equipamento.

\section{3 - Amônia}

O procedimento seguiu o método de Nessler descrito pelo fabricante do espectrofotômetro. Mediu-se $25 \mathrm{~mL}$ da amostra da água, adicionou-se 3 gotas do reagente mineral stabilizer, 3 gotas do reagente álcool polivinil, $1 \mathrm{~mL}$ do reagente reativo de Nessler, marcou-se 1 minuto, agitou-se, limpouse as cubetas e realizou-se a leitura no espectrofotômetro DR5000 no programa 380, da HATCH.

Para o branco, realizou-se o mesmo procedimento acima descrito, utilizando água destila em substituição a amostra.

\section{4 - Nitrito}

O procedimento seguiu o método descrito pelo fabricante do espectrofotômetro. Mediu-se $25 \mathrm{~mL}$ da amostra da água, adicionou-se o reagente de nitrito sachê Nitriver 3, esperou-se 20 minutos, agitouse, limpou-se as cubetas e realizou-se a leitura no espectrofotômetro DR5000 no programa 371, da HATCH. 
Para o branco, realizou-se o mesmo procedimento acima descrito, utilizando água destila em substituição a amostra.

\section{5 - Nitrato}

O procedimento seguiu o método descrito pelo fabricante do espectrofotômetro. Mediu-se $25 \mathrm{~mL}$ da amostra da água, adicionou-se o reagente de nitrato sachê Nitraver 5, agitou-se por 1 minuto, esperou-se 5 minutos para reação, limpou-se as cubetas e realizou-se a leitura no espectrofotômetro DR5000 no programa 353, da HATCH.

Para o branco, realizou-se o mesmo procedimento acima descrito, utilizando água destila em substituição a amostra.

\section{6 - DBO, DQO e Metais}

Por problemas no laboratório da SEMACE, a DBO, DQO e Manganês não foram analisados nos 08 poços externos ao aterro. Assim, os resultados desses parâmetros constantes nesse artigo referem-se exclusivamente aos 06 poços internos do aterro e ao efluente da lagoa facultativa, ambos enviados pelo operador do equipamento. Por isso os procedimentos analíticos não serão descritos.

Já o ferro foi detectado nos poços externos medindo-se $25 \mathrm{~mL}$ da amostra em uma cubeta e adicionando-se o reagente Sachê Ferrover Iron. Esse reagente não foi adicionado no branco. Esperou-se 3 minutos, mexeu-se, limpou-se a cubeta e foi feita a leitura no espectofotômetro DR5000, programa 255.

\section{7 - Legislação Ambiental}

De posse dos resultados, comparou-se os laudos referentes aos poços internos (apresentados pelo operador do aterro) com os dos poços externos (coletados e analisados pela SEMACE) para verificar se há ou não influência da disposição dos resíduos sólidos na qualidade da água subterrânea da área de influência direta do aterro sanitário.

Para a água subterrânea, todos os parâmetros foram comparados com a Resolução do Conselho Nacional do Meio Ambiente No 396/2008, Anexo I, com exceção do parâmetro Amônia que foi comparado com o Decreto No 12.486/78, do estado de São Paulo.

Para a DBO, foi utilizada como referência a Resolução do Conselho Nacional do Meio Ambiente $\mathrm{N}^{\mathrm{o}} 357$, de 17 de março de 2005, que dispõe sobre a classificação dos corpos de água e diretrizes ambientais para o seu enquadramento.

Para a DQO e para o efluente da lagoa facultativa, foi utilizada como referência a Portaria da SEMACE $N^{\circ} 154$, de 22 de julho de 2002, que dispõe sobre padrões e condições de lançamento de efluentes líquidos por fontes poluidoras. 


\section{4 - RESULTADOS E DISCUSSÕES}

\section{1 - Cloretos}

A Tabela 03, a seguir, apresenta os resultados enviados pelo operador do ASMOC referentes à concentração de cloretos nos poços na área interna, entre os meses de agosto de 2014 e julho de 2015, respeitando a frequência bimestral solicitada pela SEMACE. Por motivos desconhecidos, esse parâmetro não foi monitorado no mês de setembro de 2015 .

Tabela 03: Concentração de Cloretos, em mg/L, nos poços na área interna do ASMOC, de acordo com o monitoramento enviado pelo operador do aterro

\begin{tabular}{cccccccc}
\hline MÊS/ANO & PADRÃO & P 01 AM & P 02 AM & P 03 AM & P 01 AJ & P 02 AJ & P 03 AJ \\
\hline AGO/2014 & 250,00 & 601,00 & 692,00 & $3.052,00$ & 158,00 & 61,20 & $1.190,00$ \\
OUT/2014 & 250,00 & 533,00 & 910,00 & $4.453,00$ & 81,40 & 63,10 & $2.178,40$ \\
DEZ/2014 & 250,00 & 564,00 & 995,30 & $3.874,00$ & 89,10 & 51,50 & $2.673,00$ \\
FEV/2015 & 250,00 & 556,20 & $2.650,00$ & $4.120,00$ & 92,70 & 58,70 & $3.199,00$ \\
MAI/2015 & 250,00 & 360,00 & 230,00 & $1.250,00$ & 85,00 & 37,00 & 120,00 \\
JUL/2015 & 250,00 & 452,70 & 273,60 & $1.423,00$ & 92,00 & 50,30 & 164,70 \\
\hline
\end{tabular}

A Tabela 04, a seguir, apresenta os resultados referentes à concentração de cloretos nos 08 poços na área externa, no mês de janeiro de 2016.

Tabela 04: Concentração de Cloretos, em mg/L, nos poços na área externa do ASMOC

\begin{tabular}{cccccccccc}
\hline MÊS/ANO & PADRÃO & P 01 & P 02 & P 03 & P 04 & P 05 & P 06 & P 07 & P 08 \\
\hline JAN/2016 & 250,00 & 369,00 & 120,00 & 955,00 & 68,00 & 131,00 & 43,00 & 153,00 & 351,00 \\
\hline
\end{tabular}

Pela Tabela 03, dos 6 poços monitorados na área interna do aterro sanitário, 4 apresentaram a concentração de cloretos acima do permitido em vários momentos (poços 01-AM, 02-AM, 03-AM e 03-AJ). Os 3 poços classificados como a montante e dentro da área do aterro, isto é, mais próximos a área de disposição dos resíduos sólidos, apresentaram concentrações acima do permitido pela Resolução do CONAMA N 396/2008. Dos 3 poços a jusante e dentro da área do aterro, 1 apresentou concentração acima do permitido (poço 03-AJ).

Pela Tabela 04, dos 8 poços externos, somente 3 apresentaram concentrações acima do padrão estabelecido pela legislação vigente, sendo 1 a montante (P-8) e 2 a jusante (P-1 e P-3), e ainda assim as concentrações encontradas nesses poços externos foram menores do que a média de concentração encontrada nos poços internos. Em relação ao poço P 03, esse consiste na amostra mais vulnerável, tendo em vista que o local estava aberto e exposto às várias intempéries ambientais e fatores externos.

Dessa forma, comparando os poços dentro do aterro com os externos, em termos de Cloretos, não se pode afirmar que as concentrações encontradas nos poços internos são em função das características 
do solo local, pois os poços externos, que estão em um raio inferior a 1.800 metros de distância dos poços internos, apresentaram concentrações muito inferiores.

Em um trabalho semelhante, apresentado no XIII Congresso Brasileiro de Águas Subterrâneas, sobre o impacto da qualidade das águas subterrâneas causado pela disposição de resíduos sólidos urbanos no aterro municipal de Feira de Santana, na Bahia, cujas características geológicas são semelhantes as do ASMOC (embasamento cristalino e aquífero fissural), os autores concluíram que as concentrações de Cloretos e Sólidos Totais Dissolvidos encontradas acima do permitido indicavam alteração da qualidade da água subterrânea da área do aterro municipal pela lixiviação de compostos provenientes do lixo disposto no local (Santos et al., 2004).

\section{2 - Sólidos Totais Dissolvidos}

A Tabela 05, a seguir, apresenta os resultados enviados pelo operador do ASMOC referentes à concentração de sólidos totais dissolvidos nos poços na área interna, entre os meses de agosto de 2014 e setembro de 2015, respeitando a frequência bimestral solicitada pela SEMACE.

Tabela 05: Concentração de sólidos totais dissolvidos, em mg/l, nos poços na área interna do ASMOC, de acordo com o monitoramento enviado pelo operador do aterro

\begin{tabular}{cccccccc}
\hline MÊS/ANO & PADRÃO & P 01 AM & P 02 AM & P 03 AM & P 01 AJ & P 02 AJ & P 03 AJ \\
\hline AGO/2014 & 1000,00 & 1468,00 & $1.942,00$ & $6.515,00$ & 684,00 & 244,00 & $3.351,00$ \\
OUT/2014 & 1000,00 & 1433,00 & $1.816,00$ & $8.695,00$ & 671,30 & 295,00 & $6.056,00$ \\
DEZ/2014 & 1000,00 & 1953,00 & $2.201,00$ & $6.386,00$ & 870,00 & 283,60 & $6.537,60$ \\
FEV/2015 & 1000,00 & 1441,00 & $3.127,00$ & $8.468,00$ & 982,00 & 463,00 & $6.575,00$ \\
MAI/2015 & 1000,00 & 1228,00 & 733,70 & $2.121,00$ & 524,00 & 129,30 & 444,50 \\
JUL/2015 & 1000,00 & 1675,00 & $1.149,00$ & $3.115,00$ & 596,00 & 195,00 & 625,00 \\
SET/2015 & 1000,00 & 1406,00 & 910,00 & $2.880,00$ & 390,00 & 146,20 & 520,00 \\
\hline
\end{tabular}

A Tabela 06, a seguir, apresenta os resultados referentes à concentração de sólidos totais dissolvidos nos 08 poços na área externa, no mês de janeiro de 2016.

Tabela 06: Concentração de Sólidos Totais Dissolvidos, em mg/L, nos poços na área externa do ASMOC

\begin{tabular}{cccccccccc}
\hline MÊS/ANO & PADRÃO & P 01 & P 02 & P 03 & P 04 & P 05 & P 06 & P 07 & P 08 \\
\hline JAN/2016 & $1.000,00$ & 820,00 & 332,00 & $1.570,00$ & 288,00 & 428,00 & 246,00 & 398,00 & 742,00 \\
\hline
\end{tabular}

Pela Tabela 05, dos 6 poços monitorados na área interna do ASMOC, 4 apresentaram a concentração de sólidos totais dissolvidos acima do permitido em vários momentos (poços 01-AM, 02AM, 03-AM e 03-AJ). Dos 3 poços a montante e dentro da área do aterro, todos apresentaram concentração acima do permitido. De um total de 21 análises (7 de cada poço a montante), 19 
apresentaram valores acima do padrão estabelecido pela legislação vigente, com uma média de $1.514,85,1.696,95$ e $5.454,28 \mathrm{mg} / \mathrm{L}$ respectivamente para os poços 01-AM, 02-AM e 03-AM.

Já para os poços externos, dos 8 poços monitorados somente 1 (P-03) apresentou concentração acima do permitido e todas as concentrações encontradas nesses poços foram bem inferiores as encontradas nos poços internos. Novamente, o poço P-03 aparece com qualidade inferior, quando comparado aos outros poços, provavelmente devido a sua maior vulnerabilidade pelos motivos já explicitados acima.

Vale ressaltar que os poços dentro da área do aterro e classificados como a montante estão bem próximos da área de disposição dos resíduos, indicando que a qualidade da água desses poços pode estar sendo influenciada pela lixiviação de compostos provenientes do lixo disposto no local.

Lembra-se também que as células de disposição desse aterro não possuem impermeabilização sintética, tendo sido compactada apenas com argila.

Comparando então os resultados de sólidos totais dissolvidos encontrados nos poços internos com os poços externos, não se pode afirmar que os resultados dos poços internos são consequência das características do terreno, porque os poços externos apresentaram concentrações muito inferiores.

\section{3 - Compostos Nitrogenados}

A Tabela 07, a seguir, apresenta os resultados enviados pelo operador do ASMOC referentes à concentração de Nitrato nos poços na área interna, entre os meses de agosto de 2014 e setembro de 2015, respeitando a frequência bimestral solicitada pela SEMACE.

Tabela 07: Concentração de Nitrato, em mg/L, nos poços na área interna do ASMOC, de acordo com o monitoramento enviado pelo operador do aterro

\begin{tabular}{cccccccc}
\hline MÊS/ANO & PADRÃO & P 01 AM & P 02 AM & P 03 AM & P 01 AJ & P 02 AJ & P 03 AJ \\
\hline AGO/2014 & 10,00 & 0,15 & 1,64 & 18,60 & 0,10 & 7,74 & 1,76 \\
OUT/2014 & 10,00 & 0,94 & 2,15 & 19,32 & 0,54 & 8,12 & 2,44 \\
DEZ/2014 & 10,00 & 0,34 & 1,80 & 3,16 & 0,49 & 2,96 & 0,46 \\
FEV/2015 & 10,00 & 0,55 & 0,54 & 3,12 & 0,14 & 1,86 & 0,40 \\
MAI/2015 & 10,00 & 0,03 & 0,36 & 3,04 & 2,64 & 2,94 & 0,13 \\
JUL/2015 & 10,00 & 0,07 & 1,15 & 3,01 & 0,79 & 2,79 & 2,43 \\
SET/2015 & 10,00 & 1,71 & 2,60 & 2,98 & 0,97 & 2,83 & 1,01 \\
\hline
\end{tabular}

Amônia, nitrato e nitrito são substâncias químicas encontradas em baixas concentrações de forma natural na água e no subsolo. A deposição de matéria orgânica no solo pode aumentar drasticamente a quantidade de nitrogênio. Esse nitrogênio é biotransformado e transforma-se, por fim, na substância inorgânica denominada nitrato, caracterizado por possuir elevado grau de mobilidade no solo, alcançando o manancial subterrâneo e ali se depositando. Por possuir estas características, o nitrato se 
torna um bom indicativo para avaliar se um dado manancial subterrâneo está sendo contaminado pela atividade antrópica sobre ele exercida (Mello e Brasil, 1984).

Pela Tabela 07, o nitrato só apresentou-se fora do padrão no poço 03 AM nas coletas de agosto e dezembro de 2014. Ou seja, ao avaliar-se o nitrato isoladamente não se poderia afirmar que está havendo uma interferência por parte do aterro, mas quando se verifica os níveis de amônia, observa-se que somente o poço 02 AM não apresentou amônia em desacordo, conforme observado na Tabela 08, a seguir.

Tabela 08: Concentração de Amônia, em mg/L, nos poços na área interna do ASMOC, de acordo com o monitoramento enviado pelo operador do aterro

\begin{tabular}{lccccccc}
\hline MÊS/ANO & PADRÃO & P 01 AM & P 02 AM & P 03 AM & P 01 AJ & P 02 AJ & P 03 AJ \\
\hline AGO/2014 & 3,50 & 0,08 & 0,77 & 0,14 & 8,03 & 0,08 & 1,28 \\
OUT/2014 & 3,50 & 2,45 & 0,75 & 0,41 & 10,35 & 1,37 & 2,02 \\
DEZ/2014 & 3,50 & 3,48 & 1,68 & 2,33 & 3,98 & 1,12 & 2,95 \\
FEV/2015 & 3,50 & 0,01 & 0,03 & 3,18 & 3,15 & 2,32 & 4,26 \\
MAI/2015 & 3,50 & 0,09 & 0,18 & 2,45 & 3,21 & 0,19 & 0,20 \\
JUL/2015 & 3,50 & 0,19 & 0,21 & 3,18 & 5,50 & 0,16 & 0,48 \\
SET/2015 & 3,50 & 13,10 & 0,00 & 3,02 & 12,5 & 0,66 & 22,2 \\
\hline
\end{tabular}

Segundo Biguelini e Gumy, 2012, apesar de no Brasil a legislação federal não estabelecer limite para as concentrações de nitrogênio amoniacal em águas subterrâneas, devido aos seus efeitos adversos à saúde considera-se importante a sua inclusão. Por isso esse parâmetro foi monitorado tendo como referência o Decreto Estadual No 12.486/78, do estado de São Paulo, que refere-se a águas de consumo alimentar e estabelece padrões para águas de poço captadas por qualquer processo e que não sofreram qualquer tratamento. Dessa forma, considerando esse decreto, todos os poços monitorados na área interna, com exceção do poço 02 AM, apresentaram amônia em desacordo, em especial o poço 01 AJ em que, das 7 coletas realizadas, 5 apresentaram amônia não conforme, com uma média de concentração de $6,71 \mathrm{mg} / \mathrm{L}$.

Tabela 09: Concentração de Nitrito, em mg/L, nos poços na área interna do ASMOC, de acordo com o monitoramento enviado pelo operador do aterro

\begin{tabular}{lccccccc}
\hline MÊS/ANO & PADRÃO & P 01 AM & P 02 AM & P 03 AM & P 01 AJ & P 02 AJ & P 03 AJ \\
\hline AGO/2014 & 1,00 & 0,00 & 0,00 & 0,05 & 0,01 & 0,00 & 0,14 \\
OUT/2014 & 1,00 & 1,15 & 0,00 & 0,02 & 1,73 & 0,98 & 0,05 \\
DEZ/2014 & 1,00 & 0,42 & 0,00 & 0,05 & 0,10 & 0,40 & 0,08 \\
FEV/2015 & 1,00 & 0,59 & 0,53 & 0,18 & 0,06 & 0,53 & 0,08 \\
MAI/2015 & 1,00 & 0,02 & 0,09 & 0,12 & 0,08 & 0,00 & 0,04 \\
JUL/2015 & 1,00 & 0,00 & 0,07 & 0,00 & 0,30 & 0,14 & 0,07 \\
SET/2015 & 1,00 & 0,07 & 0,00 & 0,00 & 0,06 & 0,00 & 0,29 \\
\hline
\end{tabular}


A Tabela 09, acima, apresenta os resultados enviados pelo operador do ASMOC referentes à concentração de Nitrito nos poços na área interna, entre os meses de agosto de 2014 e setembro de 2015, respeitando a frequência bimestral solicitada pela SEMACE. Por essa Tabela 09, observa-se que somente os Poços 01 AM e 01 AJ, nas coletas de outubro de 2014, apresentaram-se em desacordo com a legislação vigente para o parâmetro Nitrito.

A Tabela 10, a seguir, apresenta os resultados referentes à concentração de Nitrato, Nitrito e Amônia nos 08 poços na área externa, no mês de janeiro de 2016.

Tabela 10: Concentração de Nitrato, Nitrito e Amônia, em mg/L, nos poços na área externa do ASMOC em janeiro de 2016

\begin{tabular}{cccccccccc}
\hline PARÂMETRO & PADR ÃO & P 01 & P 02 & P 03 & P 04 & P 05 & P 06 & P 07 & P 08 \\
\hline NITRATO & 10,00 & 10,80 & 20,30 & 30,00 & 26,00 & 11,00 & 16,00 & 28,00 & 22,00 \\
NITRITO & 1,00 & 0,09 & 0,01 & 0,09 & 0,02 & 0,04 & 0,04 & 0,00 & 0,01 \\
AMÔNIA & 3,50 & 0,12 & 0,08 & 0,70 & 0,05 & 0,11 & 0,50 & 0,10 & 0,20 \\
\hline
\end{tabular}

Em relação a concentração de amônia, nitrito e nitrato nos poços externos, nenhum poço apresentou amônia e nitrito em desacordo, mas todos os 8 apresentaram nitrato acima do permitido. Em relação especificamente a amônia, as concentrações encontradas foram bem inferiores as encontradas nos poços internos.

Como o nitrogênio amoniacal é um dos primeiros passos da decomposição da matéria orgânica, sua presença indica contaminação recente e poderia estar relacionada à construção precária dos poços, mas essa hipótese foi descartada para o caso em tela, uma vez que o operador do aterro garantiu que os poços internos foram construídos corretamente. Outra possibilidade é a falta de proteção do aquífero.

Em relação as diferenças encontradas para as concentrações de amônia, nitrito e nitrato nos poços internos à área do aterro, Biguelini e Gumy, 2012, afirmam que essa diferença ocorre porque nem sempre os três compostos de nitrogênio analisados estão presentes simultaneamente numa mesma amostra, devido à origem da água e da fonte de contaminação. Portanto, a ausência de nitrato não significa que amônia e nitrito estejam ausentes.

Os resultados, portanto, indicam que a água subterrânea da área interna do aterro pode estar sofrendo influência da lixiviação de compostos provenientes do lixo disposto no local.

\section{4 - Demanda Bioquímica de Oxigênio (DBO) e Demanda Química de Oxigênio (DQO)}

As Tabelas 11 e 12, a seguir, apresentam os resultados enviados pelo operador do ASMOC referentes à concentração de DBO e DQO nos poços na área interna, entre os meses de agosto de 2014 e setembro de 2015, respeitando a frequência bimestral solicitada pela SEMACE. 
Tabela 11: Concentração de $\mathrm{DBO}$, em mg/ $\mathrm{L} \mathrm{O}_{2}$, nos poços na área interna do ASMOC, de acordo com o monitoramento enviado pelo operador do aterro

\begin{tabular}{ccccccc}
\hline MÊS/ANO & P 01 AM & P 02 AM & P 03 AM & P 01 AJ & P 02 AJ & P 03 AJ \\
\hline AGO/2014 & 12,00 & 29,00 & 54,00 & 21,00 & $<2,00$ & 179,00 \\
OUT/2014 & 15,00 & 37,00 & 41,00 & 18,00 & 3,00 & 166,00 \\
DEZ/2014 & $<2,00$ & 32,00 & 49,00 & 16,00 & $<2,00$ & 197,00 \\
FEV/2015 & $<2,00$ & 34,00 & 67,00 & 19,00 & 9,00 & 132,00 \\
MAI/2015 & 3,00 & 25,00 & 47,00 & 13,00 & $<2,00$ & 12,00 \\
JUL/2015 & 34,00 & 31,00 & 51,00 & 29,00 & $<2,00$ & 32,00 \\
SET/2015 & 5,30 & $<2,00$ & 34,00 & $<2,00$ & $<2,00$ & 18,50 \\
\hline
\end{tabular}

Tabela 12: Concentração de DQO, em mg/L $\mathrm{O}_{2}$, nos poços na área interna do ASMOC, de acordo com o monitoramento enviado pelo operador do aterro

\begin{tabular}{ccccccc}
\hline MÊS/ANO & P 01 AM & P 02 AM & P 03 AM & P 01 AJ & P 02 AJ & P 03 AJ \\
\hline AGO/2014 & 17,00 & 51,00 & 95,00 & 36,00 & 6,00 & 310,00 \\
OUT/2014 & 24,00 & 64,00 & 84,00 & 29,00 & 8,00 & 295,00 \\
DEZ/2014 & 5,00 & 57,00 & 96,00 & 37,00 & 5,00 & 346,00 \\
FEV/2015 & 8,40 & 61,00 & 118,00 & 41,00 & 17,6 & 269,00 \\
MAI/2015 & 15,50 & 44,20 & 83,00 & 30,40 & 7,10 & 21,40 \\
JUL/2015 & 61,50 & 51,20 & 92,50 & 52,00 & 6,00 & 58,40 \\
SET/2015 & 9,00 & 8,30 & 67,30 & $<2,00$ & $<2,00$ & 33,30 \\
\hline
\end{tabular}

Apesar da Resolução do CONAMA No 396/2008 não estabelecer padrão para DBO, os mesmos foram monitorados nos poços internos à área do ASMOC e os resultados foram comparados com o padrão estabelecido pela Resolução do CONAMA N 357/2005, que trata das características de águas superficiais. Essa resolução estabelece um padrão de DBO para recursos hídricos superficiais de Classe 2 e Classe 3 com os respectivos valores, 5 e $10 \mathrm{mg} / \mathrm{L} \mathrm{O}_{2 . .}$ Considerando que as águas subterrâneas possuem um poder de autodepuração menor que as águas superficiais, supõe-se que o valor de DBO encontrado nas mesmas deva ser menor.

Partindo dessa premissa, comparando com Rios de Classe 2, o Poço 01-AM apresentou 4 análises acima do padrão, das 7 realizadas. O poço 02-AM apresentou 6 análises acima do padrão, das 7 realizadas. O poço 03-AM apresentou 7 análises acima do padrão, das 7 realizadas. O poço 01-AJ apresentou 6 análises acima do padrão, das 7 realizadas. O poço 02-AJ apresentou 1 análise acima do padrão, das 7 realizadas. O poço 03-AJ apresentou 7 análises acima do padrão, das 7 realizadas.

Comparando com Rios de Classe 3, o Poço 01-AM apresentou 3 análises acima do padrão, das 7 realizadas. O poço 02-AM apresentou 6 análises acima do padrão, das 7 realizadas. O poço 03-AM apresentou 7 análises acima do padrão, das 7 realizadas. O poço 01-AJ apresentou 6 análises acima do padrão, das 7 realizadas. O poço 02-AJ não apresentou nenhuma análise acima do padrão, das 7 realizadas. O poço 03-AJ apresentou 7 análises acima do padrão, das 7 realizadas. 
Se compararmos com a concentração de DBO da Portaria SEMACE no $154 / 2002$, que trata de efluente tratado e estabelece um padrão de $60 \mathrm{mg} / \mathrm{L} \mathrm{O}_{2}$ para $\mathrm{DBO}$, o poço $03 \mathrm{AJ}$ merece atenção pois em várias campanhas os resultados apresentaram-se superior ao que é estabelecido por essa portaria.

A resolução do CONAMA N ${ }^{\circ} 357 / 2005$ não estabelece um padrão de DQO, mas ao compararmos novamente com a Portaria SEMACE No 154/2002, cujo padrão de DQO é 200 mg/L O somente o poço 03-AJ apresentou-se com concentrações acima do que é permitido para efluentes tratados.

Esses resultados de DBO, portanto, demonstram que talvez as águas subterrâneas da área interna do ASMOC estejam sofrendo influência do aterro sanitário e corroboram com as concentrações de nitrogênio amoniacal encontradas nos mesmos poços, indicando provável influência de matéria orgânica.

Esses parâmetros não foram analisados nos 8 poços externos cuja água foi coletada no dia 26/01/2016 por problemas no laboratório da SEMACE.

\section{5 - Metais}

Entre os meses de agosto de 2014 e julho de 2015, o operador do aterro enviou os monitoramentos da água dos poços internos referentes aos metais Ferro, Mercúrio, Alumínio, Cobalto, Cádmio, Chumbo, Cobre, Cromo total, Manganês, Molibdênio, Níquel, Prata, Vanádio e Zinco. Desses metais, o ferro e o manganês apresentaram concentrações acima do padrão estabelecido pela Resolução do CONAMA No 396/2008 em alguns momentos. Dessa forma, apresenta-se, a seguir, nas Tabelas 13 e 14, os resultados de ferro e manganês nos poços internos apresentados pelo operador do aterro e na Tabela 15 os resultados desses parâmetros nos poços externos coletados e analisados pela SEMACE. Por motivos desconhecidos, o operador do aterro não analisou esses metais em setembro de 2015.

Tabela 13: Concentração de Ferro nos poços internos do ASMOC, de acordo com o monitoramento enviado pelo operador do aterro

\begin{tabular}{ccccccc}
\hline MÊS/ANO & P 01 AM & P 02 AM & P 03 AM & P 01 AJ & P 02 AJ & P 03 AJ \\
\hline AGO/2014 & 0,12 & 0,25 & 0,16 & 0,19 & 0,06 & 0,78 \\
OUT/2014 & 0,17 & 0,29 & 0,18 & 0,22 & 0,05 & 0,65 \\
DEZ/2014 & 0,23 & 0,12 & 0,34 & 0,81 & 0,11 & 0,65 \\
FEV/2015 & 0,17 & 0,19 & 0,38 & 0,97 & 0,17 & 0,59 \\
MAI/2015 & 0,21 & 0,14 & 0,12 & 1,13 & 0,12 & 0,27 \\
JUL/2015 & 0,80 & 0,16 & 0,04 & 0,89 & 0,15 & 0,04 \\
\hline
\end{tabular}


Tabela 14: Concentração de Manganês nos poços internos do ASMOC, de acordo com o monitoramento enviado pelo operador do aterro

\begin{tabular}{ccccccc}
\hline MÊS/ANO & P 01 AM & P 02 AM & P 03 AM & P 01 AJ & P 02 AJ & P 03 AJ \\
\hline AGO/2014 & 0,042 & 0,008 & 0,008 & 0,021 & 0,009 & 0,075 \\
OUT/2014 & 0,012 & 0,011 & 0,019 & 0,090 & 0,006 & 0,015 \\
DEZ/2014 & 0,132 & 0,009 & 0,046 & 0,153 & 0,005 & 0,231 \\
FEV/2015 & 0,080 & 0,130 & 0,120 & 0,150 & 0,080 & 0,130 \\
MAI/2015 & 0,000 & 0,100 & 0,100 & 0,100 & 0,000 & 0,000 \\
JUL/2015 & 0,000 & 0,000 & 0,100 & 0,000 & 0,000 & 0,000 \\
\hline
\end{tabular}

Pela Tabela 13, observa-se que o Ferro apresentou-se fora do padrão de 0,30 mg/L estabelecido pela Resolução do CONAMA No 396/2008 em 11 análises, nos poços 01AM, 03AM, 01AJ e 03AJ.

Em relação ao Manganês, pela Tabela 14, os poços 01 AM, 02 AM, 03 AM, 01 AJ e 03 AJ apresentaram concentração desse metal acima do permitido. Entretanto, as concentrações detectadas para esse elemento não foram tão superiores ao limite máximo permitido, já que o padrão é $0,1 \mathrm{mg} / \mathrm{L}$ e os resultados foram $0,132 \mathrm{mg} / \mathrm{L}, 0,130 \mathrm{mg} / \mathrm{L}, 0,120 \mathrm{mg} / \mathrm{L}, 0,153 \mathrm{mg} / \mathrm{L}, 0,150 \mathrm{mg} / \mathrm{L}, 0,231 \mathrm{mg} / \mathrm{L}$ e $0,130 \mathrm{mg} / \mathrm{L}$.

A presença desses metais pode ser considerada como oriunda da dissolução de compostos do solo ou de despejos industriais. Entretanto, uma investigação mais detalhada do comportamento desses metais na água desses poços deve ser feita, concluindo pela sua associação ou não a operação do aterro sanitário ou à características do próprio terreno.

Em relação aos poços externos monitorados no dia 26/01/2016, devido o laboratório da SEMACE não realizar as análises de todos os metais, à época, somente o ferro foi analisado, apresentando-se dentro do padrão em todos os poços, de acordo com a Tabela 15.

Tabela 15: Concentração de Ferro, em mg/L, nos poços na área externa do ASMOC em janeiro de 2016

\begin{tabular}{cccccccccc}
\hline PARÂMETRO & PADRÃO & P 01 & P 02 & P 03 & P 04 & P 05 & P 06 & P 07 & P 08 \\
\hline FERRO & 0,30 & 0,10 & 0,02 & 0,04 & 0,03 & 0,01 & 0,30 & 0,01 & 0,02 \\
\hline
\end{tabular}

\section{6 - Efluente da Lagoa Facultativa}

A Tabelas 16, a seguir, apresenta os resultados enviados pelo operador do ASMOC referente à análise do efluente contido na lagoa facultativa do aterro, entre os meses de agosto de 2014 e setembro de 2015, respeitando a frequência bimestral solicitada pela SEMACE. 
Tabela 16: Concentração de Amônia, Nitrato, Nitrito, Cloreto, Sólido Totais Dissolvidos (STD), Demanda Bioquímica de Oxigênio (DBO), Demanda Química de Oxigênio (DQO), Ferro e Manganês, em mg/L, no efluente contido na lagoa facultativa do ASMOC, de acordo com o monitoramento enviado pelo operador do aterro

\begin{tabular}{cccccccccc}
\hline MÊS/ANO & Amônia & Nitrato & Nitrito & Cloretos & STD & DBO & DQO & Ferro & Manganês \\
\hline AGO/2014 & 8,60 & 3,17 & 0,13 & 3.905 & 11.276 & 1.248 & 2.080 & 3,29 & 0,872 \\
OUT/2014 & 6,52 & 2,37 & 0,15 & 3.689 & 11.493 & 1.902 & 3.245 & 4,12 & 0,764 \\
DEZ/2014 & 10,22 & 5,71 & 0,12 & 3.566 & 11.350 & 1.850 & 3.200 & 4,46 & 0,210 \\
FEV/2015 & 5,91 & 2,92 & 0,17 & 3.117 & 10.980 & 846 & 1.272 & 5,47 & 0,171 \\
MAI/2015 & 6,84 & 2,48 & 0,23 & $2.726,30$ & 9.660 & 636 & 1.045 & 4,59 & 0,074 \\
JUL/2015 & 5,19 & 2,90 & 0,14 & 2.923 & 9.862 & 684 & 1.180 & 4,61 & 0,052 \\
SET/2015 & 14,70 & 3,03 & 0,16 & 4.580 & 10.800 & 1.250 & 3.050 & 5,51 & 0,650 \\
\hline
\end{tabular}

Pela Tabela 16, ao compararmos com o padrão estabelecido pela Portaria SEMACE $\mathrm{N}^{\circ}$ 154/2002 para Amônia (20,0 mg/L, quando pH acima de 8,0), Ferro (15 mg/L) e Manganês (1,0 $\mathrm{mg} / \mathrm{L}$ ), observa-se que em todas as campanhas esses parâmetros apresentaram-se abaixo do limite máximo permitido. Ressalta-se que em todas as campanhas, o $\mathrm{pH}$ manteve-se acima de 8,0. Os parâmetros Nitrato, Nitrito, Cloretos e Sólidos Totais Dissolvidos não possuem padrão estabelecido por essa portaria.

Em relação a DBO e DQO, cujo padrão estabelecido pela Portaria SEMACE No 154/2002 é 60 e $200 \mathrm{mg} / \mathrm{L} \mathrm{O}_{2}$, respectivamente, todas as campanhas apresentaram-se fora do padrão.

Por esses resultados, infere-se que o sistema de tratamento de chorume do aterro não está sendo eficiente e o chorume pode estar influenciando a qualidade da água subterrânea na área interna do aterro.

Outra observação que se pode fazer é em relação aos parâmetros Cloretos e Sólidos Totais Dissolvidos que, apesar de não possuírem padrão estabelecido para efluente tratado, apresentaram valores de concentração bem elevados.

\section{5 - CONCLUSÃO}

Tomando por base os resultados das análises físico-químicas da água dos 6 poços de monitoramento na área interna do ASMOC, quando comparadas com os resultados dos 8 poços externos, coletados no dia 26/01/2016, além das características do efluente da lagoa facultativa, acredita-se haver indícios de comprometimento da qualidade da água subterrânea na área interna do aterro em função das atividades de operação do mesmo. Tal conclusão se baseia principalmente nos resultados de Cloretos, Sólidos Totais Dissolvidos, Nitrogênio Amoniacal e DBO. Quanto aos metais, somente o ferro e o manganês apresentaram-se em concentração acima do permitido em alguns momentos nos poços internos, podendo ser considerada, a priori, como consequência da dissolução de 
compostos do solo. Quanto a DQO, o poço 03 AJ merece atenção especial, pois foi o único que apresentou concentrações acima do permitido, em alguns momentos, para esse parâmetro, quando comparado com a Portaria SEMACE N $\mathrm{N}^{\mathrm{B}}$ 154/2002, que foi usada apenas para se ter uma noção de nível de concentração de DQO nos poços, já que a Resolução Nº 396/2008, do Conselho Nacional do Meio Ambiente não estabelece valor para esse parâmetro.

Desse modo, é provável que o ASMOC apresente falhas na sua construção, gerenciamento e operação, como possíveis vazamentos no sistema de impermeabilização das três lagoas de estabilização do chorume ou na impermeabilização das células do próprio aterro. Vale lembrar que esse aterro não possui impermeabilização sintética, apenas compactação com argila.

Para confirmar se há realmente contaminação da água subterrânea na área de influência desse aterro sanitário, sugere-se um monitoramento rigoroso e uma avaliação do passivo ambiental em solo e água subterrânea, de acordo com as normas NBR 15515, partes 1, 2 e 3, da Associação Brasileira de Normas Técnicas.

Quanto as análises dos poços externos, sugere-se que sejam feitas, no mínimo, mais quatro amostragens realizadas em intervalos de três meses, conforme recomenda a norma NBR 13896:1997, da Associação Brasileira de Normas Técnicas (ABNT, 1997). Caso confirmado a contaminação, sugere-se a apresentação de um Plano de Recuperação de Área Degradada, dando ênfase aos recursos hídricos.

\section{6 - REFERÊNCIAS BIBLIOGRÁFICAS}

ASSOCIAÇÃO BRASILEIRA DE NORMAS TÉCNICAS. NBR 13896: Aterros de Resíduos Não Perigosos - Critérios para Projeto, Implantação e Operação. Rio de Janeiro: [s.n], 1997.

ASSOCIAÇÃO BRASILEIRA DE NORMAS TÉCNICAS. NBR 15495: Poços de monitoramento de águas subterrâneas em aqüíferos granulados - Parte 1: Projeto e construção. Rio de Janeiro: [s.n], 2007.

ASSOCIAÇÃO BRASILEIRA DE NORMAS TÉCNICAS. NBR 15495: Poços de monitoramento de águas subterrâneas em aqüíferos granulares - Parte 2: Desenvolvimento. Rio de Janeiro: [s.n], 2008.

ASSOCIAÇÃO BRASILEIRA DE NORMAS TÉCNICAS. NBR 15515-1: Passivo ambiental em solo e água subterrânea - Parte 1: Avaliação preliminar. Rio de Janeiro: [s.n], 2007.

ASSOCIAÇÃO BRASILEIRA DE NORMAS TÉCNICAS. NBR 15515-2: Passivo ambiental em solo e água subterrânea - Parte 2: Investigação confirmatória. Rio de Janeiro: [s.n], 2011. 
ASSOCIAÇÃO BRASILEIRA DE NORMAS TÉCNICAS. NBR 15515-3: Passivo ambiental em solo e água subterrânea - Parte 3: Investigação detalhada. Rio de Janeiro: [s.n], 2013.

BIGUELINI, Cristina Poll; GUMY, Mariane Pavani. SAUUDE AMBIENTAL: Índices de Nitrato em Águas Subterrâneas de Poços Profundos na Região Sudoeste do Paraná. Revista Faz Ciência, Francisco Beltrão, v. 14, n. 20, p.153-175, dez. 2012.

BRASIL. Resolução n ${ }^{\circ}$ 357, de 17 de março de 2005. Dispõe sobre a classificação dos corpos de água e diretrizes ambientais para o seu enquadramento, bem como estabelece as condições e padrões de lançamento de efluentes, e dá outras providências.. Resolução Conama No 357. Brasília, 18 mar. 2005.

BRASIL. Resolução $n^{0}$ 396, de 03 de abril de 2008. Dispõe sobre a classificação e diretrizes ambientais para o enquadramento das águas subterrâneas e dá outras providências. Resolução Conama No 396. Brasília, 07 abr. 2008.

CEARÁ. Portaria $n^{\circ} 154$, de 22 de julho de 2002. Dispõe sobre padrões e condições para lançamento de efluentes líquidos gerados por fontes poluidoras. Portaria Semace $\mathbf{N}^{\mathbf{0}}$ 154. Fortaleza, 01 out. 2002.

MARISETE DANTAS DE AQUINO (Org.). Relatório de Impacto Ambiental do Aterro Sanitário Oeste. Fortaleza: Astef, 1989.

MELLO, F.A.F.; MOACYR, O. C. SOBRINHO, B.; ARZOLLA, S.; SILVEIRA, R.I.; COBRA NETTO, A.; KIEH, J.C. Fertilidade do Solo, $2^{\circ}$ edição. Livraria Nobel S.A., São Paulo, 1984.

MOR, S.; RAVINDRA, K.; DAHIYA, R. P.; CHANDRA, A. Leachate characterization and assessment of groundwater pollution near municipal solid waste landfill site. Environmental Monitoring and Assessment. Nova Délhi, India, n. 118, p. 435 - 456, 2006.

POHLING, Rolf; FERREIRA, Rosa de Lisieux Urano de Carvalho; FARIAS, Magda Kokay. Manual de Procedimentos Laboratoriais: Métodos Analíticos para Água e Ar Aplicados na SEMACE. Fortaleza: Superintendência Estadual do Meio Ambiente, 2005.

SANTOS, Cristovaldo Bispo dos et al. Caracterização do Impacto na Qualidade das Águas Subterrâneas Causado pela Disposição dos Residuos Sólidos Urbanos no Aterro Municipal da Cidade 
de Feira de Santana - BA. In: CONGRESSO BRASILEIRO DE ÁGUAS SUBTERRÂNEAS, XIII., 2004, São Paulo. Anais... . São Paulo: Abas, 2004. p. 1 - 17.

SÃO PAULO. Decreto n ${ }^{\circ}$ 12486, de 20 de outubro de 1978. Aprova Normas Técnicas Especiais Relativas a Alimentos e Bebidas. Decreto No 12486. São Paulo, 21 out. 1978. 